\title{
ABSORBED DOSES FOR PATIENTS UNDERGOING PANORAMIC RADIOGRAPHY, CEPHALOMETRIC RADIOGRAPHY AND CBCT
}

\author{
MALGORZATA WRZESIEN' ${ }^{1}$ and JERZY OLSZEWSKI ${ }^{2}$ \\ ${ }^{1}$ University of Lodz, Łódź, Poland \\ Department of Nuclear Physics and Radiation Safety \\ ${ }^{2}$ Nofer Institute of Occupational Medicine, Łódź, Poland \\ Department of Radiological Protection
}

\begin{abstract}
Objectives: Contemporary dental radiology offers a wide spectrum of imaging methods but it also contributes to an increase in the participation of dental radiological diagnosis in the patient's exposure to ionizing radiation. The aim of this study is to determine the absorbed doses of the brain, spinal column, thyroid and eye lens for patients during panoramic radiography, cephalometric radiography and cone beam computed tomography (CBCT). Material and Methods: The thermoluminescent dosimetry and anthropomorphic phantom was used for measuring the doses. The 15 panoramic, 4 cephalometric and 4 CBCT exposures were performed by placing high-sensitivity thermoluminescent detectors (TLD) in 18 anatomical points of the phantom. Results: The maximum absorbed dose recorded during performed measurements corresponds to the point representing the brainstem and it is $10 \mathrm{mGy}$. The dose value recorded by the TLD placed in the thyroid during CBCT imaging in relation to the panoramic radiography differs by a factor of 13.5 . Conclusions: Cone beam computed tomography, in comparison with panoramic or cephalometric imaging technique, provides higher radiation doses to the patients. Int J Occup Med Environ Health 2017;30(5):705-713
\end{abstract}

Key words:

Thermoluminescence, Panoramic radiography, Absorbed dose, CBCT, Cephalometric radiography,

Thermoluminescent detectors

\section{INTRODUCTION}

The development of dental diagnostics and the availability of dental X-ray - as well as the necessity of dental X-ray images before, during, and after endodontic, orthodontic and implantology treatments - requires an increase in the number of radiological images taken. As a result, the percentage share of dental radiological diagnosis in the patient's exposure to ionizing radiation increases. However, an integral part of radiology is exposure of patients and, potentially, clinical staff to X-rays. No exposure to X-rays may be considered to be completely free of risk, so the use of radiation by dentists is accompanied by the responsibility to ensure appropriate protection [1]. In Europe, diagnostic radiology represents the largest man-made contribution to the dose received by the population [2]. This observation also applies to both developing and developed countries [3]. It is estimated that in 2014 the average Pole's exposure from sources of radiation

Received: March 8, 2016. Accepted: July 25, 2016.

Corresponding author: M. Wrzesień, University of Lodz, Department of Nuclear Physics and Radiation Safety, Pomorska 149/153, 90-236 Łódź, Poland (e-mail: mwrzesien@uni.lodz.pl). 
used for medical purposes, mainly for medical diagnostics, was $0.86 \mathrm{mSv}$ [4]. International radiation protection standards have recommended that diagnostic reference levels meet the requirements imposed by the optimization and reduction of patients' dose [5,6]. Diagnostic reference level values are the doses in medical diagnostic practice that relates to the typical examinations, for groups of standardized patients or standard phantoms, for broadly defined types of radiological equipment [6,7].

Increased use of radiological imaging in dentistry has increased the importance of using optimal X-ray operating parameters, making it possible to obtain a diagnostically fullvalue image while optimizing exposure. The main aim of this exposure is to lower the dose of ionizing radiation for the patient during the examination. Much research on measuring and estimating patients' doses has been published, using a variety of the radiographic techniques, operational parameters, and different patient exposure regions [6,8-14]. This paper intends to determine the absorbed doses to the brain, spinal column, eye lens and thyroid in an anthropomorphic phantom for a selection of panoramic, cephalometric radiography and cone beam computed tomography (CBCT) equipment, using thermoluminescent dosimetry.

\section{MATERIAL AND METHODS}

\section{Detectors}

High-sensitivity thermoluminescent detectors (TLDs) made of lithium fluoride (MCP-N (LiF: $\mathrm{Mg}, \mathrm{Cu}, \mathrm{P}$ ) produced by the Polish company Radcard, were used for determining the doses. The detectors are small (diameter of $4.5 \mathrm{~mm}$, thickness of $0.9 \mathrm{~mm}$ ) and reusable. The absorption properties of the detectors are comparable with those of the human soft tissues. The detectors may be used for measuring doses ranging from $2 \mu \mathrm{Sv}$ to $10 \mathrm{~Sv}[15,16]$. The readings of the dosimeters were read out using an RA'04 reader from Mikrolab, Poland. The TLDs were subjected to a typical process of annealing in a TLD oven produced by PTW and could be used in subsequent measurements. Before the measurements, the TL detectors had been exposed in a ${ }^{137} \mathrm{Cs} \gamma$ beam, with an air kerma of $1 \mathrm{mGy}$. Only detectors, the response of which was within the range of mean \pm standard deviation were deemed appropriate for the measurements. Through this selection process, a batch of about 300 TL detectors was selected.

\section{Phantom}

The measurements were performed with head-neck slices of an anthropomorphic Rando phantom (Photo 1a and 1b).
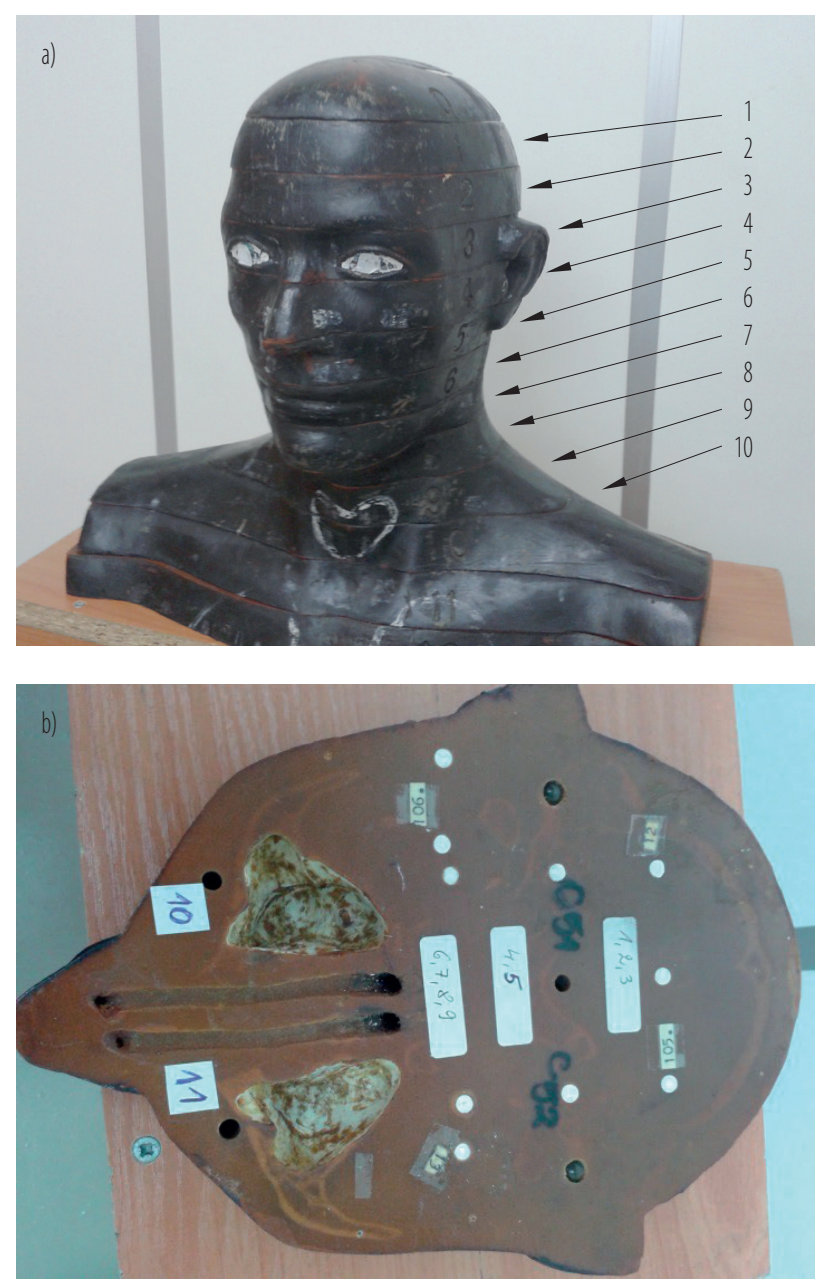

Photo 1. Anthropomorphic Rando phantom: a) marked successive slices, $b$ ) a single slice with marked holes where thermoluminescent detectors (TLD) were inserted 
This corresponds to the outside measurement of the average human being (height of $175 \mathrm{~cm}$ and weight of $73.5 \mathrm{~kg}$ ). A phantom consists of a human skeleton covered in a tissue-like material.

\section{Calibration of detectors}

Thermoluminescent detector energy response was studied using RQR Narrow compliant with PN-EN 61267 at the Secondary Standard Calibration Laboratory [17]. The value of the dose rate was measured by using an ionization chamber of reference device - UNIDOS. Temperature and pressure corrections were taken into account. The distance between the source and the phantom was $2 \mathrm{~m}$. The values of calibration coefficients had been determined for each measurement point individually. Thermoluminescent detectors were calibrated in terms of the dose absorbed by air.

\section{Methods}

The Rando phantom was positioned for panoramic, cephalometric and CBCT radiography without the TLDs. The exposure settings recommended by the manufacturer for the particular image and patient size were used. For the dose measurements, the detectors were placed in transparent foil. Background radiation was taken into account during the measurement as well. The TLDs were attached at 18 anatomical points of a Rando phantom. Additionally, in the case of panoramic exposure, 2 TL detectors were placed on the surface of the Rando phantom at the level of the right and left lens of the eye and the left and right side of thyroid gland. The tissues/organs in which the absorbed dose was measured and the number of TLDs used are presented in the Table 1. Measurements were made in a variety of dental offices, using different dental imaging units and the radiographic settings used in the routine exposures, too (the exposure settings recommended by the manufacturer). Two series of 5 measurements each were performed by 2 dental panoramic devices - Orthoralix 9200 and Ko-
Table 1. Location of the thermoluminescent detectors (TLD) in the anthropomorphic Rando phantom

\begin{tabular}{|c|c|}
\hline Organ/Tissue/Slice of phantom & TLD number \\
\hline \multicolumn{2}{|l|}{ Middle point of brain } \\
\hline 1 & 1 \\
\hline 2 & 2 \\
\hline 3 & 3 \\
\hline 4 & 4 \\
\hline \multicolumn{2}{|l|}{ Center of the spinal column } \\
\hline 5 & 5 \\
\hline 6 & 6 \\
\hline 7 & 7 \\
\hline 8 & 8 \\
\hline 9 & 9 \\
\hline 10 & 10 \\
\hline \multicolumn{2}{|l|}{ Thyroid } \\
\hline \multicolumn{2}{|l|}{9} \\
\hline right & $\mathrm{T} 1$ \\
\hline center & $\mathrm{T} 2$ \\
\hline left & $\mathrm{T} 3$ \\
\hline \multicolumn{2}{|l|}{10} \\
\hline right & $\mathrm{T} 4$ \\
\hline center & $\mathrm{T} 5$ \\
\hline left & T6 \\
\hline \multicolumn{2}{|l|}{$\begin{array}{l}\text { Surface of the phantom at the level } \\
\text { of the thyroid gland }\end{array}$} \\
\hline \multicolumn{2}{|l|}{9} \\
\hline right side & $\mathrm{T} 7$ \\
\hline left side & $\mathrm{T} 8$ \\
\hline \multicolumn{2}{|l|}{ Eye lens } \\
\hline \multicolumn{2}{|l|}{3} \\
\hline right & E1 \\
\hline left & E2 \\
\hline right surface & E3 \\
\hline left surface & E4 \\
\hline
\end{tabular}

dak 9000, as well as 5 single exposures - by Kodak 9000, Kodak 8000, PaX-500, PaX-Reve 3D and Orthoralix 9200. The operational parameters of exposure for each of devices are provided in the Table 2. 
Table 2. The radiographic settings of devices used in absorbed dose measurements

\begin{tabular}{|c|c|c|c|}
\hline \multirow[b]{2}{*}{$\mathrm{X}$-ray technology/Device } & \multicolumn{3}{|c|}{ Settings } \\
\hline & $\begin{array}{c}\text { voltage of the tube } \\
{[\mathrm{kV}]}\end{array}$ & $\begin{array}{c}\text { current } \\
{[\mathrm{mA}]}\end{array}$ & $\begin{array}{c}\text { time exposure } \\
{[\mathrm{s}]}\end{array}$ \\
\hline \multicolumn{4}{|l|}{ Panoramic radiography } \\
\hline Orthoralix 9200 & 70 & 6 & 12.0 \\
\hline Kodak 9000 & 70 & 8 & 14.3 \\
\hline Kodak 9000 & 70 & 10 & 14.3 \\
\hline Kodak 8000 & 73 & 12 & 13.9 \\
\hline $\mathrm{PaX}-500$ & 70 & 8 & 12.9 \\
\hline PaX-Reve 3D & 75 & 8 & 12.0 \\
\hline \multicolumn{4}{|l|}{ Cephalometric radiography } \\
\hline Orthoralix 9200 & 80 & 7 & 8.0 \\
\hline Kodak $8000 \mathrm{C}$ & 80 & 10 & 0.5 \\
\hline $\mathrm{PaX}-500$ & 78 & 9 & 0.9 \\
\hline \multicolumn{4}{|l|}{ Cone beam computed tomography (CBCT) } \\
\hline Kodak $9000 \mathrm{C}$ & 70 & 10 & 32.4 \\
\hline GX-CB 500 & 120 & 5 & 23.0 \\
\hline PaX-Reve 3D & 85 & 5 & 25.0 \\
\hline
\end{tabular}

Cephalometric exposures were performed by using: Orthoralix 9200 (twice), Kodak $8000 \mathrm{C}$ and PaX-500. In the case of CBCT technique, 5 exposures were performed by using Kodak 9000 C device (twice), GX-CB 500, PaXReve 3D (twice). After each exposure, the detectors were removed and read.

For the purpose of the analysis of the results, Mann-Whitney $\mathrm{U}$ statistical test was used.

\section{RESULTS}

\section{Panoramic radiography}

The highest doses ( \pm standard error) during panoramic radiography were recorded by TL detectors identified as 6,7 and 5 (the center of the spinal column). They are as follows: $2.43 \pm 0.03 \mathrm{mGy}, 2.13 \pm 0.14 \mathrm{mGy}$, and $1.87 \pm 0.07 \mathrm{mGy}$, respectively. The TLDs recorded the highest doses for the points which were positioned in the rotational plan of the image. Comparable values of absorbed doses were recorded in the middle point of the brain.
For thyroid gland the highest absorbed dose $(0.17 \pm 0.04 \mathrm{mGy})$ was recorded by TLDs placed at the T2 point.

The use of an anthropomorphic phantom allowed for the placement of detectors inside as well as on the surface of the phantom. The absorbed dose values at the points identified as the right and left side of the thyroid gland differed in a statistically significant way ( $\mathrm{p} \leq 0.05$ ).

It should be noted in the analysis of the eye lenses exposure during the panoramic radiography that the dose values recorded by the TLD positioned at the points representing the left eye lens did not differ in a statistically significant way from those which were recorded by detectors placed in the point corresponding to the right eye lens $(p>0.05)$. The measurements carried out by using an anthropomorphic phantom allowed for the placement of detectors not only in the position of the eye lens but also on the surface of the phantom at the level of the lens of the eye. There was no statistically significant difference between the values of the absorbed dose registered in the points 
corresponding to the position of the left and right lens of the eye as compared to the doses recorded at the level of eye lens $(p>0.05)$.

\section{Cephalometric radiography}

The highest doses ( \pm standard error) during cephalometric radiography were recorded by TLDs identified as 1 , 2 and 3 (Table 1). They are as follows: $0.69 \pm 0.03 \mathrm{mGy}$, $0.30 \pm 0.01 \mathrm{mGy}$, and $0.273 \pm 0.003 \mathrm{mGy}$, respectively.

Differences in the technique of the cephalometric exam, compared with the panoramic radiography technique, resulted in a different type of exposure of the points in the brain and spinal column. The lowest doses were recorded at the points corresponding to the spinal column. The highest doses for the 3 points located in the thyroid gland were: $32.5 \pm 0.02 \mu \mathrm{Gy}$ (T2), 32.4 $\pm 0.03 \mu \mathrm{Gy}$ (T3), $16.23 \pm 0.01 \mu \mathrm{Gy}$ (T1), respectively. The absorbed doses recorded by TLDs in points located within the Rando phantom, slice No. 10 (T4-T6), were on average 3 times lower as compared with the absorbed doses recorded within slice No. 9 (T1-T3).

The maximum value of the dose absorbed by the right eye lens was $80.0 \pm 0.7 \mu \mathrm{Gy}$. Comparison of the dose absorbed by the right and left lens of the eye during the cephalometric radiography showed no statistically significant difference $(p>0.05)$.

\section{Exposure of the brain and spinal column}

\section{during extraoral dental diagnostics}

Absorbed dose values recorded at the respective measuring points using CBCT exposure technique have been compared to 2 already researched exposure techniques in dentistry.

The Figure 1 presents the values of the dose absorbed by the middle point of brain and spinal column during panoramic radiography, cephalometric radiography and CBCT. The nature of exposure of measurement points located in the area of the brain, and spinal column during panoramic

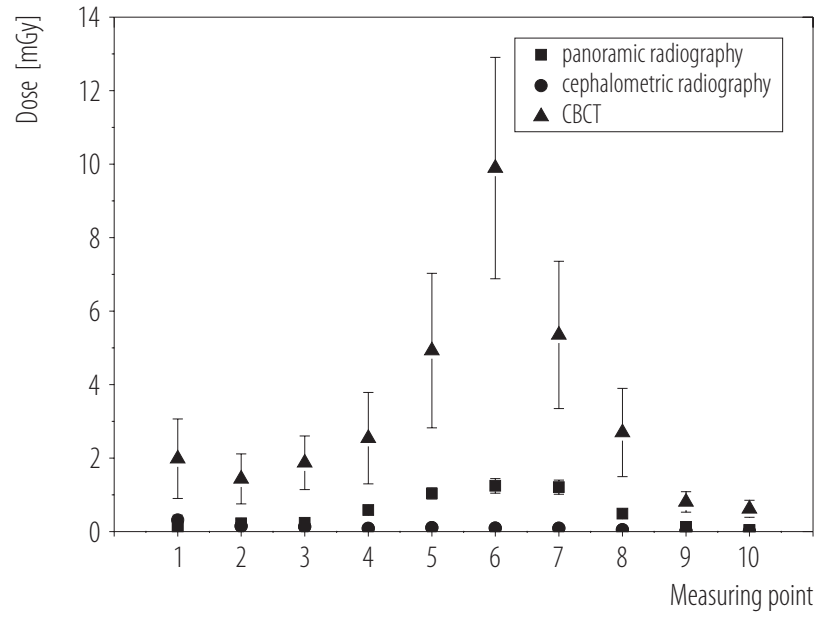

1-10 - slices of the phantom.

Fig. 1. The mean absorbed doses ( \pm standard deviation) to brain and neck structure during panoramic radiography, cephalometric radiography and cone beam computed tomography (CBCT) measured in anthropomorphic Rando phantom

radiography and $\mathrm{CBCT}$ was similar (Figure 1 ). The average absorbed dose recorded in the point 6 during the CBCT exam was as follows: $9.89 \pm 6.73 \mathrm{mGy}$, which was 8 times higher as compared to the average absorbed dose at the same point during panoramic radiography, and 100 times higher than during cephalometric radiography. The lowest radiation doses (taking into account the absorbed dose) were recorded during cephalometric radiography.

\section{Thyroid exposure during extraoral dental diagnostics}

The Figure 2 presents the values of absorbed doses to thyroid gland during panoramic radiography, cephalometric radiography and $\mathrm{CBCT}$.

In the case of the thyroid, it is difficult to discern the differences in the nature of exposure of individual data points (Figure 2). Clearly, the most spectacular difference in the case of these 3 types of exposure is the recorded absorbed dose. In this case, the largest exposure to radiation (in absorbed dose units) in dentistry still occurs during CBCT. The average absorbed dose recorded during 


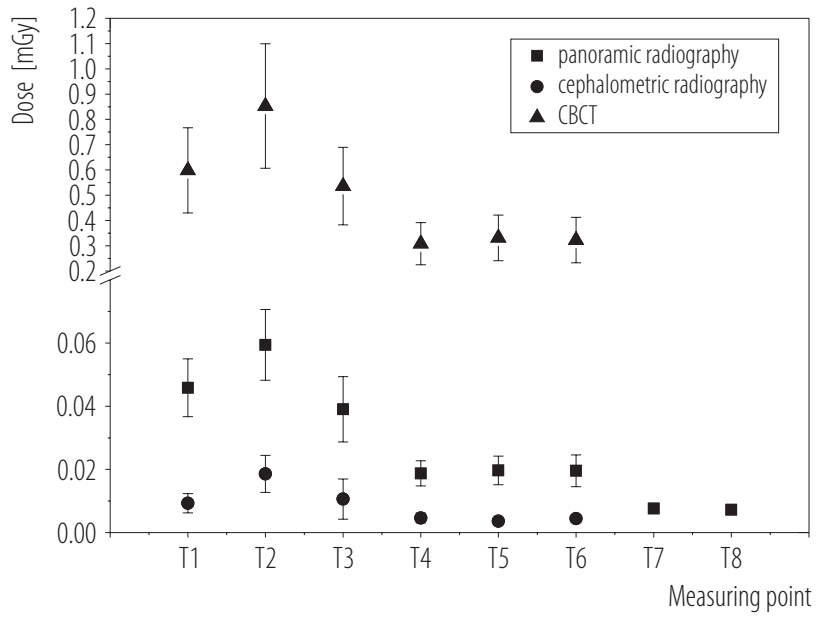

T1-T6 - within the gland, T7-T8 - on the surface of the phantom.

Fig. 2. The mean absorbed doses ( \pm standard deviation) to thyroid gland during panoramic radiography, cephalometric radiography and cone beam computed tomography (CBCT) measured in anthropomorphic Rando phantom

CBCT examination in point $\mathrm{T} 2$ was $0.85 \pm 0.55 \mathrm{mGy}$, while the average absorbed dose at the same point (T2) during panoramic radiography was 59.4 $\pm 43.4 \mu \mathrm{Gy}$ and $18.6 \pm 11.7 \mu \mathrm{Gy}$ in cephalometric radiography.

\section{Eye lens exposure during extraoral dental diagnostics}

The Figure 3 shows the values of the absorbed dose to eye lenses during panoramic radiography, cephalometric radiography and CBCT.

The Figure 3 shows the different nature of exposure between eye lenses during radiological diagnostic tests in dentistry - especially during cephalomeric radiography, as compared to panoramic radiography or CBCT. However, there were no statistically significant differences ( $p>0.05$ ) between the dose absorbed by the left and right lens in CBCT, just like the panoramic and cephalometric radiography. A clear difference remains in the values of recorded doses. Exposure of the eye lens during CBCT technique (in units of absorbed dose) is also higher in relation to the other 2 techniques. The average absorbed

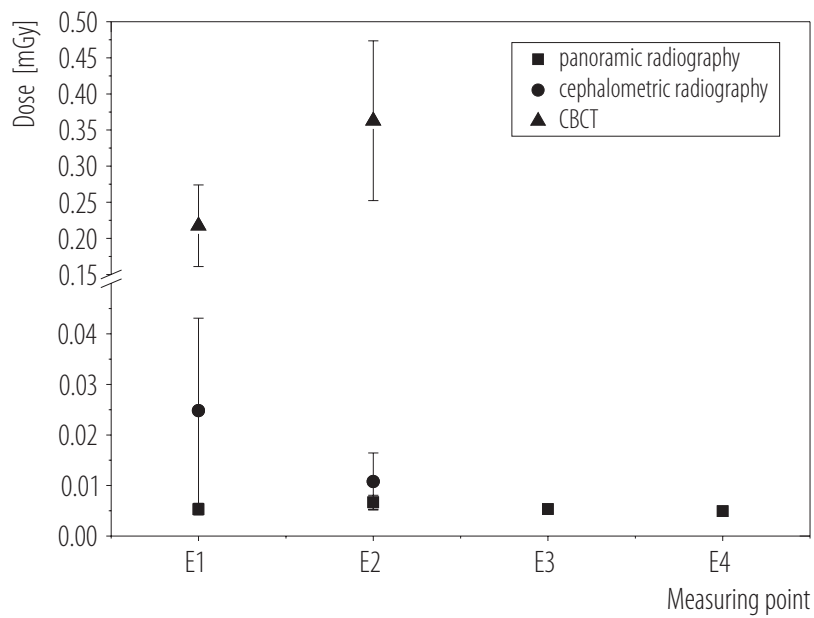

E1 - right eye lens, E2 - left eye lens; E3, E4 - points located on the surface of the phantom on the level of the right and left eye lens, respectively.

Fig. 3. The mean absorbed dose ( \pm standard deviation) to eye lens during panoramic radiography, cephalometric radiography and cone beam computed tomography (CBCT) measured in anthropomorphic Rando phantom.

dose in the left lens of the eye during CBCT examination was $0.4 \pm 0.3 \mathrm{mGy}$.

\section{DISCUSSION}

In this study, the absorbed radiation doses were measured at certain anatomical sites corresponding to head and neck areas in a Rando phantom, during panoramic radiography, cephalometric radiography and cone beam computed tomography (CBCT). The measurements were performed by using different dental imaging units during routine exposure in a variety of dental offices and different radiographic settings (recommended by the manufacturer). The lowest radiographic settings were used for 2 digital devices: Orthoralix 9200 and Kodak 9000. A comparison of the exposures performed using Kodak 9000 and Orthoralix 9200 devices shows that in the case of panoramic radiography, the doses absorbed by the patients in the region of the brain, brain stem, and at the height of the thyroid gland on the right side (the dose as measured on the surface of the phantom), are statistically different 
$(p<0.05)$. In the case of the cervical spine and the thyroid gland on the left side (the dose measured in the phantom), the right and left lens of the eye, as well as at the height of the right and left eye lenses (the surface of the phantom), there was no measured statistical difference in absorbed dose values $(\mathrm{p}>0.05)$.

Most papers concerning radiation dose estimation in panoramic radiography draw comparisons between conventional and digital panoramic radiography [11,18-20]. These studies have concluded that any dose reduction results in an image quality difference with a predominance of the conventional panoramic device [21]. Gavala et al. [8] state that the radiation risk related to panoramic radiography is still uncertain, although the absorbed doses received are low. Our results show that the average value of the dose absorbed by the thyroid during panoramic radiography is $34.4 \pm 33.9 \mu \mathrm{Gy}$, and the order of magnitude corresponds to a value obtained by Gavala et al. [8]. In the case of the eye lens, the average absorbed dose is nearly 10 times lower, as compared with the value obtained by Gavala et al. [8], and is equal to $6 \pm 5 \mu \mathrm{Gy}$. Panoramic radiography is the source of the highest doses, especially for the brain and brain stem areas. Liu et al. [22] give the absorbed dose for eye lens during 2D dental panoramic is about $4 \mathrm{mGy}$ and about $7 \mathrm{mGy}$ for the thyroid.

When comparing the doses absorbed by the right and left eye lens, no statistically significant difference ( $p>0.05)$ was found. No statistically significant differences were found, either, when comparing the doses absorbed by the thyroid and the eye lenses during cephalometric radiography.

In recent years, cone beam computed tomography $(\mathrm{CBCT})$ has become a widely accepted radiographic tool for diagnosis, treatment planning and follow-up in dentistry [13]. It provides a clear image of high contrast and is extremely useful for evaluating bone $[23,24]$. The European Commission (EC) Report 172 [1] notes that the advent of CBCT has been an enormous advance in dental imaging. It is a type of imaging technology that is entirely new to dentists. Since it is a relatively new technique, majority of dental CBCT dosimetry research has used the more recent tissue weighting factors as compared to the published works on conventional dental radiographic techniques pre-dates the recent revision of tissue weighting factors by the International Commission on Radiological Protection (ICRP) 103 [25].

It is still important to recognize that the doses reported for one dental CBCT machine may be quite different to another and that ranges of dose are more appropriate to use than absolute figures. Pauwels et al. [13] have presented data on average relative contribution of organ doses to effective dose in dental CBCT. The bulk of the contribution comes from remainder organs, salivary glands, thyroid gland and red bone marrow.

Liu et al. [22] give that for CBCT tooth doses are higher than those of 2D projection image: $3 \mathrm{D}$ imaging is about 14 times higher than 2D because 3D uses high working voltage, current, longer irradiation time and broader field size, thus doses are higher. The mean dose for midline thyroid during the CBCT phantom exposure for the setting of $15 \mathrm{~mA}, 120 \mathrm{kVp}$ is equal to $8.4 \mathrm{mGy}$ and for the mid brain the mean doses recorded by TLD is $6.03 \mathrm{mGy}$ and $5.93 \mathrm{mGy}$ for the center $\mathrm{C}$ spine [26]. Tsiklakis et al. [27] give that the thyroid gland received $0.32 \mathrm{mGy}$, the cervical spine received $1.28 \mathrm{mGy}$ and the lens of eyes $-0.61 \mathrm{mGy}$.

Soares et al. [28] note that CBCT is an imaging technique that has better three-dimensional spatial resolution and lower absorbed doses to organs/tissues than those results, usually obtained with medical computed tomography indental applications. The use of CBCT technology in clinical practice provides a number of potential advantages for maxillofacial imaging as compared with conventional CT [27,29,30]. Scarfe et al. [29] highlight that cone beam technology will become an important tool in dental and maxillofacial imaging over the next decade or two. Clinical applications of CBCT are rapidly being applied to 
dental practice. Nevertheless, taking into account the dose values recorded during diagnostic technique by $\mathrm{CBCT}$, special attention should be given to the analysis of profit and loss (regarding health) for the patient, resulting from the use of this imaging technique.

\section{CONCLUSIONS}

Thermoluminescent detectors placed at all measurement points record higher doses of ionizing radiation in the case of CBCT exposure technique. Cone beam computed tomography, in comparison with panoramic or cephalometric imaging technique, provides higher radiation doses to the patients. The maximum absorbed dose recorded during performed measurements corresponds to the point representing the brainstem and stands at $10 \mathrm{mGy}$. The dose value recorded by the TLD placed in the thyroid during CBCT imaging in relation to the panoramic radiography differs by a factor of 13.5 .

\section{ACKNOWLEDGMENTS}

The authors wish to thank all those who agreed to perform measurements in X-ray laboratories as well as for all kindness and interest they received during their research.

\section{REFERENCES}

1. European Commission. Cone beam CT for dental and maxillofacial radiology (evidence-based guidelines) [Internet]. The Commission; 2012 [cited 2015 Sep 24]. Available form: http:// bookshop.europa.eu/en/cone-beam-ct-for-dental-and-maxillofacial-radiology-pbMJXA12001/.

2. Schibilla $H$. The radiation protection research programme of the Commission of the European Communities. In: Oherhofer M, editor. Advances in radiation protection, health physics and radiation protection. Vol. 1. Norwell: Kluwer Academic Publishers; 1991.

3. Faulkner K, Broadhead DA, Harrison RM. Patient dosimetry measurement methods. Appl Radiat Isot. 1999;50:113-23, https://doi.org/10.1016/S0969-8043(98)00031-1.
4. National Atomic Energy Agency. [Annual report 2014. Annual report on the activities of the President of the National Atomic Energy Agency and assessment of nuclear safety and radiological protection in Poland in 2014] [Internet]. The Agency; 2014 [cited 2015 Sep 24]. Available from: http:// www.paa.gov.pl/sites/default/files/RaportPrezesaPAA2014. pdf. Polish.

5. International Commission on Radiological Protection. Radiological protection and safety in medicine. Ann ICRP. 1996;26(2).

6. Zenóbio MAF, da Silva TA. Absorbed doses on patients undergoing tomographic exams for pre-surgery planning of dental implants. Appl Radiat Isot. 2007;65:708-11, https:// doi.org/10.1016/j.apradiso.2007.01.016.

7. European Commission. Guidance on diagnostic reference levels (DRLs) for medical exposures. The Commission; 1999.

8. Gavala S, Donta C, Tsiklakis K, Boziami A, Kamenopoulou V, Stamatakis HC. Radiation dose reduction in direct digital panoramic radiography. Eur J Radiol. 2009;71:42-8, https://doi.org/10.1016/j.ejrad.2008.03.018.

9. Walker C, van der Putten W. Patient dosimetry and a novel approach to establishing Diagnostic Reference Levels in dental radiology. Phys Med. 2012;28:7-12, https://doi.org/ 10.1016/j.ejmp.2010.12.003.

10. Bianchi J, Goggins W, Rudolph M. In vivo, thyroid and lens surface exposure with spiral and conventional computed tomography in dental implant radiography. Oral Surg Oral Med Oral Pathol Oral Radiol Endod. 2000;90:249-53, https://doi.org/10.1067/moe.2000.107354.

11. Danforth RA, Clark DE. Effective dose from radiation absorbed during a panoramic examination with a new generation machine. Oral Surg Oral Med Oral Pathol Oral Radiol Endod. 2000;89:236-43, https://doi.org/10.1067/ moe.2000.103526.

12. Lambrecht JT, Roth J, Kiefer HP. Dose exposition from intra- and extraoral dental radiography. Int Congr Ser. 2004;1268:1147-51, https://doi.org/10.1016/j.ics.2004.03.337. 
13. Pauwels R, Beinsberger J, Collaert B, Theodorakou C, Rogers J, Walker A, et al. The SEDENTEXCT Project Consortium. Effective dose range for dental cone beam computed tomography scanners. Eur J Radiol. 2012;81:267-71, https://doi.org/10.1016/j.ejrad.2010.11.028.

14. Ludlow JB, Davies-Ludlow LE, White SC. Patient risk related to common dental radiographic examinations: The impact of 2007 International Commission on Radiological Protection recommendations regarding dose calculation. J Am Dent Assoc. 2008;139:1237-43, https://doi.org/10.142 19/jada.archive.2008.0339.

15. Niewiadomski T, Bilski P, Budzanowski M, Olko P, Ryba E. Progress in thermoluminescent dosimetry for radiation protection and medicine. Nucleonika. 1996;41(2):93-104.

16. Waligórski MPR, Lesiak J, Babula E, Byrski E, Ryba E, Olko P, et al. Application of individually calibrated solid LiF:Mg, Ti (MTS-N) detectors in clinical dosimetry. Radiat Prot Dosimetry. 1999;85(1-4):377-80.

17. BS-EN 61267: 2006. Medical diagnostic X-ray equipment Radiation conditions for use in the determination of characteristics. London: British Standards Institution; 2006.

18. Ludlow JB, Davies-Ludlow LE, Brooks SL. Dosimetry of two extraoral direct digital imaging devices: NewTom cone beam CT and Orthophos Plus PS panoramic unit. Dentomaxillofac Radiol. 2003;32:229-34, https://doi.org/10.1259/ $\mathrm{dmfr} / 26310390$.

19. Williams JR, Montgomery A. Measurement of dose in panoramic dental radiology. Br J Radiol. 2000;73(873):1002-6, https://doi.org/10.1259/bjr.73.873.11064656.

20. Gijbels F, Sanderink G, Wyatt J, van Dam J, Nowak B, Jacobs R. Radiation doses of digital cephalometric radiography. Br Dent J. 2004;197:149-52, https://doi.org/10.1038/ sj.bdj.4811532.

21. Molander B, Gröndahl H-G, Ekestubbe A. Quality of filmbased and digital panoramic radiography. Dentomaxil- lofac Radiol. 2004;33:32-6, https://doi.org/10.1259/dmfr/ 17777906.

22. Liu YC, Chuang KS, Yu CC, Hsu FY. Evaluation of the medical exposure doses regarding dental examinations with different X-ray instruments. Radiat Phys Chem. 2015;116: 386-92, https://doi.org/10.1016/j.radphyschem.2015.02.014.

23. Sukovic P. Cone beam computed tomography in craniofacial imaging. Orthod Craniofac Res. 2003;6(Suppl 1):31-6, https://doi.org/10.1034/j.1600-0544.2003.259.x.

24. Ziegler CM, Woertche R, Brief J, Hassfeld S. Clinical indications for digital volume tomography in oral and maxillofacial surgery. Dentomaxillofac Radiol. 2002;31(2):126-30, https://doi.org/10.1038/sj.dmfr.4600680.

25. International Commission on Radiological Protection. The 2007 recommendations of the International Commission on Radiological Protection. ICRP publication 103. Ann ICRP. 2007;37(2-4):1-332.

26. Palomo JM, Rao PS, Hans MG. Influence of CBCT exposure conditions on radiation dose. Oral Surg Oral Med Oral Pathol Oral Radiol Endod. 2008;105:773-82, https://doi. org/10.1016/j.tripleo.2007.12.019.

27. Tsiklakis K, Donta C, Gavala S, Karayianni K, Kamenopoulou V, Hourdakis CJ. Dose reduction in maxillofacial imaging using low dose Cone Beam CT. Eur J Radiol. 2005; 56:413-7, https://doi.org/10.1016/j.ejrad.2005.05.011.

28. Soares MR, Batista WO, Antonio PL, Caldas LVE, Maia AF. Study of effective dose of various protocols in equipment cone beam CT. Appl Radiat Isotopes. 2015;100:21-6, https:// doi.org/10.1016/j.apradiso.2015.01.012.

29. Scarfe WC, Farman AG, Sukovic P. Clinical applications of cone-beam computed tomography in dental practice. J Can Dent Assoc. 2006;72(1):75-80.

30. Siwerdsen JH, Jaffray DA. Cone-beam computed tomography with a flat-panel imager: Effects of image lag. Med Phys. 1999;26:2635-47, https://doi.org/10.1118/1.598803.

This work is available in Open Access model and licensed under a Creative Commons Attribution-NonCommercial 3.0 Poland License - http://creativecommons.org/ licenses/by-nc/3.0/pl/deed.en. 